\title{
THE SYSTEMS PSYCHODYNAMIC ROLE IDENTITY OF ACADEMIC RESEARCH SUPERVISORS
}

\author{
F. Cilliers \\ Department of Industrial and Organisational Psychology \\ University of South Africa \\ Pretoria, South Africa \\ e-mail: cillifvn@unisa.ac.za
}

\section{ABSTRACT}

Research on the unconscious role behaviour of academic research supervisors is limited. The aim of this research was to study and describe the systems psychodynamic role identity of a group of academic research supervisors. A qualitative in-depth socio-analytic interview was used as the data-gathering instrument. A convenient and purposive sample was drawn consisting of 11 supervisors at a large South African university. Systems psychodynamic role analysis was used as the method of data analysis. The findings indicated an experienced difference between the normative, existential and phenomenal roles demonstrating high levels of anxiety amongst academic research supervisors, being introjected by them and projected onto them. Recommendations for the institution and further research were formulated.

Keywords: anxiety, normative role, existential role, introjections, phenomenal role, projections, projective identification

\section{INTRODUCTION}

The conceptualisation of master's/doctoral degree academic research supervision has changed significantly in the last few years (Armstrong, Allinson and Hayes 2004, 41-45; Emilsson and Johnsson 2007, 163-165; Mackinnon 2004, 395-399; Petersen 2014, 823-828). The previous strong focus on policy development is now not only accompanied by increased competition, pressure on resources (such as time and funding) and increased research outputs, but also by a focus on the quality of the supervisor-student relationship. In this, the characteristics and experiences of successful students have been well documented (Adler and Adler 2005, 13-15; Conrad, Duren and Haworth 2002, 67-70; Emilsson and Johnsson 2007, 165-169; Gordon 2003, 156-157; Marcketti, Mhango and Gregoire 2006, 65-70; Murphy and Coleman 2004, 37; Popov 2009, 3-5; White 2007, 596-601), whereas comparatively less research is available on the characteristics and experiences of academic research supervisors. Waghid $(2015,7,15$ 22) refers to this aspect as a largely unstudied aspect of pedagogical work in academia. 


\section{Academic research supervision}

For the purpose of this research, this concept was defined as an interpersonal relationship in which students develop as critically thinking, creative problem-solving and autonomous researchers and professional scholars towards gaining research competence to complete a higher (master's and doctoral) degree research project under the guidance of academics authorised in their roles as academic research supervisors and with relevant subject and research competence (Denholm and Evans 2007; Green and Lee 1995, 41; Lee 2012, 10-12; Oost and Sonneveld 2007, 15; Trafford and Leshem 2010, 111-112; Wright, Murray and Geale 2007, 459). Originally, effective academic research supervisors were described simplistically as either being born or trained (Emilsson and Johnsson 2007, 165), after which the focus changed to their personality profile. Specifically, their intrapersonal characteristics of knowledge, understanding of complexity, interest in supervision and interpersonal characteristics of effective teaching skills, trusting others, dealing with complex relationships and knowing the impact of their own power, were studied (Lepp, Remmik, Leijen and Karm 2010, 51; Mackinnon 2004, 396-401). Research shows that many academic research supervisors have negative experiences of their task - they report on not having enough or adequate training, development, time and institutional support, feeling alone, overwhelmed and stressed, and being intimidated by university policies and procedures (Chiappetta-Swanson and Watt 1999, 48; Grossman 2016; Mackinnon 2004, 399; McNamara 2014, 3). As a consequence, these characteristics are being addressed in various training and accreditation courses focusing on professionalism, standards, supervision for the supervisor and ensuring effective performance outcomes for students (Armstrong, Allinson and Hayes 2004, 45; Kam 1997, 83-85; Lizzio and Wilson 2004, 471475).

Most researchers agree that the supervisor-student relationship is the most important factor influencing the quality and timeous completion of students' research projects (Halse and Bansel 2012, 378; Sonn 2016, 226-241; Waghid 2015, 7; Wright, Murray and Geale 2007, 459). The description of this relationship and its quality varies, depending on the researcher's philosophical and academic focus. For some, the optimal relationship is framed as a socially constructed collaborative partnership between supervisors, students and other members of the academic community, based on their lived experiences (Armstrong 2004, 561; Ferris 2002, 186; 2003, 377). For others, supervision is seen as constituting a learning alliance between multiple institutional agents or stakeholders (Van Biljon and De Villiers 2013, 1) grounded in a relational ethic of mutual responsibility (Halse and Bansel 2012, 381). Also, the relationship is seen as being embedded in the compatibility between student and supervisor (Armstrong, Allinson and 
Hayes 2004, 45). The preferred characteristics of supervisors are listed as cognitive (understanding, boundary setting), affective (encouragement, warmth, honesty, trust, rapport, empathy) and behavioural (collaboration, support) academic (commitment, expectations of the work and its outcomes) and ethical (Chikte and Chabilall 2016; Lepp et al. 2010, 5; Mackinnon 2004, 399-403). Supervision is also seen as a dynamic relationship because the academic research supervisors’ professional identity changes in the eyes of the student during the research project (Haamer, Lepp and Reva 2012, 112). An ineffective academic supervision relationship is characterised by personality differences and clashes, a lack of guidance and direction in structuring, planning, organising and time scaling, and a situation where the academic research supervisors' knowledge and interests do not match the research topic (Adler and Adler 2005, 12; Aguinis and Nesler 1996, 267).

From an organisational psychology stance, the academic supervision relationship is seen as comprising two roles. According to Grant $(2003,177)$ and implied by Chikte and Chabilall (2016), the academic research supervisor assumes the role of the senior partner with the credentials of relevant qualifications, often professional registration, subject knowledge and experience in teaching and research. In terms of personality, academic research supervisors should preferably be sensitively aware of their own intellectual, functional and subjective motivations (Hockey 1996, 493) and be able to give support, show enthusiasm, facilitate quality, innovate, integrate, direct, coordinate, guide and mentor students as future researchers (Chikte and Chabilall 2016, 60-65; Wright et al. 2007, 461). In their managerial role, academic research supervisors need to define the task of supervision according to the situation and the students' needs (Kam 1997, 85-89; Lee 2012, 38) and focus on structuring and controlling the training and development of the students' competencies (Wright et al. 2007, 467). Students assume the role of the junior partner which is described as receiving encouragement towards academic freedom in their exploration of knowledge (Hockey 1996, 493-499).

Almost all research on the academic research supervisors' role focuses on conscious behaviour from a behaviouristic, humanistic, social and positive psychology perspective and using quantitative research (Mmako and Schultz 2016). For example, Govender and Ramroop (2013) found that supervisors' perception of organisational climate influences their perception of the quality of the supervision. Still within these perspectives, interesting qualitative research showed how the use of narrative enquiry (through listening and responding to one-another's stories) enhances supervisors' self-belief, resourcefulness and interpersonal support, all contributing to become better academics (Pithouse-Morgan, Masinga, Naicker, Hlao and Pillay 2016, 224-244). Van Laren, Pithouse-Morgan, Chisanga, Harrison, Meyiwa, Muthukrishna, 
Naicker and Singh $(2014,1)$ used metaphor drawings and imaging towards understanding and optimising the supervision role. Coldwell, Papageorgiou, Callaghan and Fried (2016, 80-105) provided evidence of the communality of role experiences amongst South African and Swedish academic supervisors in terms of the nature of the helping relationship, academic citizenship and experiences of well-being.

Hardly any research could be found on and little is known about how the role is experienced unconsciously and how it affects the academic research supervisor. Some studies refer to depth psychology constructs but without directly studying unconscious role behaviour. For example, Damonse and Nkomo (2012) referred to the role of leadership amongst academic research supervisors and showed how academic role modelling serves as positive influencer in the intellectual development of researchers. Mackinnon (2004, 395-400) and Wright et al. (2007, 458) refer to role complexity, Aguinis and Nesler (1996, 267-280) to power, and Hammer et al. $(2012,110)$ to how the academic research supervisors' professional identity changes in the eyes of the student during the research project. All of these studies argue that as long as the unconscious behaviour remains unknown, it will influence the relationship mostly negatively and possibly even destructively. In his impressive narrative on doctorate supervision Waghid (2015, 15-27) describes his own journey as student and promoter. This is based on the philosophy of education and specifically democratic education theory focussing on amongst others the individualisation of knowledge, socialisation into the doctorate study and pragmatism leading to doctorate work as a manifestation of a creative consensus through establishing a democratic encounter aimed as scholarly and intellectual growth (Waghid 2015, 62-67). In this vein the role of the supervisor is seen as establishing a socially just democratic encounter consisting of rationality, attention to emotions, attachment, compassion, friendship (to love in view of knowledge), inclusivity, responsibility and hope. Although not specifically referring to or interpreting unconscious behavioural dynamics, Waghid (2015, 15-27) refers to concepts such as attachment, implying using the self as psychological instrument and taking on an object relations position.

The present research links with the above and further focuses on the unconscious role behaviour of the academic research supervisor while using systems psychodynamics as a theoretical container (Sievers 2009, 87). Various authors have confirmed the gravitas of this stance to provide an understanding of systemic unconscious role behaviour from a depth psychology perspective and to translate that into action in order to move the system along towards self-insight and higher levels of productivity (Czander 1993, 18; Diamond and Allcorn 2009, 1-9; Kets de Vries, Korotov and Florent-Treacy 2007, 3-13). 


\section{Systems psychodynamics}

Systems psychodynamics (SP) is theoretically informed by Freudian social and systemic psychoanalysis, family psychology, group and object relations, and systems thinking (Colman and Bexton 1975, 1-43; Colman and Geller 1985, 1-127; Cytrynbaum and Noumair 2004, 1117). SP consists of a depth psychology, developmentally focused, psycho-educational organisational theory and an interpretive stance towards the understanding of systemic conscious and unconscious behaviour (Brunner, Nutkevitch and Sher 2006, 3-13; Huffington, Armstrong, Halton, Hoyle and Pooley 2004, 109; Klein 2005). Consciousness (the 'tip of the iceberg') refers to rational day-to-day behaviour in the self and human relationships while working on the sophisticated organisational task (López-Corvo 2003, 39-41). Unconsciousness refers to systemic behaviour below the water in the iceberg metaphor and contains the experienced anxiety, irrationality and its defensive structures (Klein 1997, 61-88) while working on the basic assumption task (López-Corvo 2003, 39-41). Anxiety is defined as fear of the future, the experience underlying any systemic experience of intense emotions, mental anguish, anticipation and dread about something unexpected, unpleasant and unwanted, such as the loss of love objects and desired parts of the system's identity (Armstrong and Rustin 2015, 39-48; Curtis 2015, 31-35). Anxiety can be categorised as free floating (not linked to a specific object), survival (being physically or emotionally threatened), performance (having to execute a task), persecutory (feeling victimised) or paranoid (feeling threatened) (Long 2006, 280-285). Coping with anxiety implies using defence mechanisms (Blackman 2004, 1-16) with the purpose of protection and survival. Defences can be classified as realistic (real danger that needs responding to), neurotic (repression, regression, sublimation, transference), psychotic (splitting, projection, projective identification) and perverse (denial of reality, acting in an entitled manner, displacing objects) (Long 2008, 15-38).

Anxiety serves as the driving force of workplace systemic relatedness and manifests as follows at all systemic levels (Armstrong and Rustin 2015, 151; Huffington et al. 2004, 107118; Cytrynbaum and Noumair 2004, 389): Micro level: personal anxiety associated with coping with complex emotional factors, task anxiety generated by work; meso level: role anxiety associated with systemic representation, group anxiety generated by organisational structures manifesting as the basic assumptions of dependence (the need for a perceived strong parental object or saviour), fight/flight (responses towards or away from danger towards survival), pairing (merging with similarity as defence against alienation and loneliness), meness (differentiation from the system), and we-ness (relinquishing individuality to merge with 
groupishness); macro level: existential anxiety associated with organisational survival.

To take up an organisational role is defined as consciously being appointed in a task position as well as unconsciously managing the complexity where person and institution meet in the exercise of representation of self and other (Campbell and Groenbaek 2006, 13-32). Role consists of the normative, experiential and phenomenal parts (Obholzer and Roberts 1994, 30), and the experienced difference between these represents systemic anxiety (Armstrong and Rustin 2015, 151). The normative contains the conscious, rational and measurable work components. The existential contains the system's introjections defined as unconscious incorporation of external ideas, feelings, attitudes and values into the system's mind and behaviour - the external is taken into the inner self (Klein 1997, 9-11). The phenomenal contains the unconscious projections and projective identifications about competence received from the other, as well as the projections made onto the other. Projection refers to unconscious transferences of the system's own impressions and feelings (often unwanted, disowned, denied, unacceptable, undesired, unrecognised or ambivalent experiences) to external objects or persons. The capacity to attribute certain mental contents from one system to another can alter the behaviour of that system through the identification with the contents, which is referred to as projective identification (French and Vince 1999, 58). The system's valence (disposition) determines the projections it identifies with.

Role identity comprises the following domains: Task is the basic component of role where the primary task contains anxiety, and off-task/anti-task behaviour indicates high levels of freefloating anxiety (Neumann, Kellner and Dawson-Shepherd 1997, 160). Boundaries (e.g. ego, time, task, territory, organisational structure) refer to the either tight or loose permeable space around and between parts of the role system, keeping it safe and contained or causing vulnerability or suspicion (Diamond and Allcorn 2009, 4, 35). Authority refers to the right given to be working on the primary task as a result of rank or office occupancy, to issue commands and to punish violations (Czander 1993, 266-293). Authority is bestowed (in terms of the organigram in the mind) from above (the organisation, leadership), the side (colleagues), below (subordinates) and from within (self-authorisation). Containment refers to holding one's own and others' transformational anxiety as a potential space where thinking can move from elementary to complex (Clarke, Hahn and Hoggett 2008, 141-160; Zinkin 1989, 227-230). Role identity is seen as the integration of the above elements making the system similar to and different from others (Campbell and Groenbaek 2006, 80). Identity manifests in how the system consciously (normatively) and unconsciously (existentially, phenomenally) assumes its role, manages the primary task and the different relevant boundary conditions, authorises itself and 
others, and contains anxiety towards rational thinking (Sievers 2009, 58-61).

Applied to academic research supervisors, SP can be used to study their role behaviour in terms of contradictory thoughts that generate tensions in the mind and inhibit authenticity, creativity and keep the system in control and in a pleasing mode (Campbell and Huffington 2008, 143-146; Neumann et al. 1997, 117-118). Lucey and Rogers (2007, 16-25) hypothesised about how the above unconscious power dynamics negatively influence the supervisor-student relationship and inhibit research project progress. Gordon (1995, 154-160) studied the unconscious symbolic representation of academic research supervisors to students and reported on how idealised transference leads to positive identification, whereas negative identification may lead to narcissistic injury, resulting in a negative supervision experience. Grant (2003, 174-186) and Lepp et al. (2010, 1-5) studied how the present supervision behaviour of academic research supervisors is unconsciously impacted by their past experiences. Through regression as defence, they unconsciously allow their own past student-in-supervision feelings of gratitude, frustration, resentment and disappointment to enter into their present role as supervisor. Although previous research provides valuable insights into some psychodynamic behaviour of academic research supervisors, their SP role identity has not yet been studied. It also needs to be mentioned that when research studies the conscious relationship between supervisor and student, the student is normally included as a subject and a person. In this systems psychodynamic research, the student is not studied as a person but as an unconscious object representation in the mind of the supervisor (Armstrong 2005, 1-9). Moreover, the student is one of many such objects, including colleagues and the institution as whole.

\section{Research purpose, question, aim and contribution}

The purpose of this study was to extend academia's understanding of the systems psychodynamic role identity of academic research supervisors. The aim of the research was to study and describe the systems psychodynamic role identity of a group of academic research supervisors. The contribution of the research lies in the explication of how academic research supervisors are unconsciously taking up their role and how that can assist in the understanding of what they bring to their role, what they project onto and into the other (students, colleagues, management) and what systemic behaviours are projected onto and into them.

\section{METHODOLOGY}

In this study, systems psychodynamics served as the disciplinary relationship (Huffington et al. 2004, 11-27). Qualitative research in the psychosocial tradition (Clarke and Hoggett 2009, 1- 
22) was chosen to describe the lived experiences of the researched (Leavy 2014, 30). Hermeneutic phenomenology was chosen as the interpretive stance defined as the interpretation of text based the epistemological assumption that empathetic listening allows for deep understanding of shared experiences (Alvesson and Sköldberg 2010, 91-140). The study allowed for an in-depth description of the academic research supervisors' unconscious behaviour when working in role as a contemporary and real-life experience in a bounded system (Clarke and Hoggett 2009, 1-22).

The research was set in a large South African university where the researcher was a staff member. He assumed the role of participant observer using the self as the research tool or instrument (Clarke and Hoggett 2009, 145-163).

Sampling was convenient and purposive (Wagner, Kawulich and Garner 2012, 86-99) and included 11 academics (average age of 48, four women, seven men) with between seven and 16 years of master's and doctoral supervision experience in three colleges at the University (Economic and Management Sciences, Humanities, Education).

Congruent to the behavioural assumptions of SP and the hermeneutic lenses, data gathering was conducted by means of a 90-minute socio-analytic interview (Long 2013, 91104). This is defined as a qualitative in-depth interview operating according to an existential and phenomenological approach to uncover, understand and hypothesise about thoughts and feelings related to unconscious systemic processes and dynamics that support, obscure and influence experiences. The planning and execution of the interview entailed putting mechanistic boundaries in place (preparation, room setup, note taking, ethics) as well as dynamically ensuring a safe contained space. The interview consisted of the introduction (explaining purpose, conditions and participant consent), the questions and the review of the conversation. The opening question was framed as follows: 'The primary task of the interview is to explore your experiences of taking up the role as an academic research supervisor at this university. Where would you like to start?' The interviewer's responses include observation, active listening, clarifying, challenging, empathising, encouraging free association and note taking. The participant is provided the space to 'think the unknown known' and to access the unconscious infinite (López-Corvo 2003, 301). The interviews were tape recorded and transcribed.

Data analysis consisted of systems psychodynamic role analysis incorporating the following hermeneutic steps (Alvesson and Sköldberg 2010, 91-105): (1) studying the text for understanding and the discovery of themes, patterns, trends, narratives and critical incidents; (2) identifying the systems psychodynamic behaviours with the focus on role behaviour; and 
(3) interpreting role experiences differentiated as normative, existential and phenomenal (Obholzer and Roberts 1994, 30). Data interpretation took the hermeneutic circle into account (Alvesson and Sköldberg 2010, 105) where each unique individual experience was considered in relation to its meaning in the collective, which again could only be understood in respect of its constituent parts.

Scientific rigour and trustworthiness were ensured as follows (Graneheim and Lundman 2004, 105-108). Dependability was ensured in the process of enquiry and the rigour applied in the planning and execution of the research project. Credibility was ensured through a relatively intense research engagement and the authorised involvement of all parties (Hirschhorn 1997, 2-13). Because of his own involvement in supervision and working with colleagues, the researcher was especially aware of the insider-outsider dialogue in his mind and consequently tried to stay true to the voices of the researched while at the same time trying to answer the research question (Terre Blanche, Durrheim and Painter 2006, 399). Internal generalisability and conformability were attended to by having an independent psychologist (practising in SP) scrutinise the interpretation. She declared the research dependable and agreed on its richness (Hollway and Jefferson 2010, 26-38). The thick and detailed data description of the experiences served the purpose of transferring the meaning to different and yet similar contexts. Conformability was established through the author's attempts to examine the product to attest that the findings, interpretations and recommendations were supported by the theoretical data. Ethicality referred to informed consent and anonymity negotiated with all participants during the data-gathering phase (De Vos, Strydom, Fouché and Delport 2002, 65-66).

The findings are presented for the three conscious and unconscious role parts. The discussion explicates the manifested individual, social and system domain defences, and concludes with the integrated role identity. Lastly, the limitations and recommendations are formulated.

\section{FINDINGS}

The manifesting normative (conscious), existential and phenomenal (unconscious) role behaviour was as follows:

\section{Normative role}

Participants described the academic research supervisor role with reference to the university policies on supervision, and explained the role and its relevant procedures, expectations and outcomes clearly and logically. Some had attended training workshops and conferences in 
academic supervision at various universities. Most participants proudly described their role as of great academic importance to ensure master's and doctoral student throughput, to develop students' research competence and to create and publish knowledge in their subjects. Some referred to supervision as a key performance indicator of senior academics being assessed in their annual performance review.

\section{Existential role}

Participants described their introjections as a conflict between 'wanting to do it well', 'be the best academic supervisor to the student' and 'our subject/department', versus 'I am often uncertain' 'whether I am doing it right', 'not always knowing the real what and how' of supervision, 'doubting my competence', having 'a fear of failure', 'humiliation' and ‘embarrassment in case my student fails’.

Participants' anxiety about their role content related to the process and outcome of supervision. The process was experienced as 'daunting' and 'almost threatening' to 'my selfimage' 'in spite of having done my own master's and doctorate' and 'my own publishing record'. The research topics represented an unknown to many participants ('they are all very different', 'you can't know everything about all of them'). The research design represented a threat to their own knowledge and experience ('I often struggle with knowing which method fits the research question', 'although you may know theoretically what to do', 'you don't always cope in practice'). Most participants expressed a longing for structure ('if only we can follow a template' 'to make it controllable'). The research projects' outcome was experienced as anxiety provoking, especially with regard to the acceptance of the students' dissertation/theses by examiners (before the student hands in 'I know I have to judge the research content' and 'make a decision about the quality and the standard', but 'the criteria are so vague!').

Participants' relationships with their students were described as 'stressful', 'unpredictable', 'sometimes overwhelming', and 'the aspect of my work that puts me off most' ('I am always nervous about a new student', 'I wonder if I will be able to cope with the content', 'design' and 'the communication issues'). They referred to how they 'hate it when a student sends in a chapter' for review, 'let alone a full thesis' (because 'it disrupts my whole life', 'planning' and 'schedule'). They would often procrastinate 'which does not work' - 'you just feel guilty' and 'shameful' for 'not being a good supervisor'. They mentioned their 'intense frustration' when students do not understand the complexity of the research or academic style ('where do you draw the line between my role as supervisor and the students' task to do the research themselves?'). Many participants mentioned that they often 'think that I am not up to 
this topic' or 'to deal with a student'.

Some participants coped with the situation by 'over-preparing for a student feedback appointment', because 'you do not want to make a mistake' or 'be seen as stupid'. One participant reminded herself of occasions where 'my own issues and nervousness just confused the student more'. Some participants mentioned how their supervision task reminded them of being at school and university - where 'tight time deadlines' and 'performance criteria' were set by the authorities, and 'you just have to sink or swim'. These defences of regression and transference tie in with previous research (Grant 2003, 174; Lepp et al. 2010, 1) on how present supervision behaviour is unconsciously impacted by past experiences.

\section{Phenomenal role}

Participants experienced projections of competence and incompetence from below (students), from the side (colleagues) and from above (authority figures representing the department, college and university).

From below, the projections of competence onto the participants were about the students' dependence on the supervisor as the authority figure ('sometimes the students want us to do everything for them', 'even rescue them in case their examiners disapprove of their work', 'one student said in the class how glad she was that I am her promoter because I will do the work for her', 'they think I know it all’). Projections of incompetence were as follows: Students projected their anger about their incompetence to cope with the demands of research ('she was very angry at me when she realised that I will not search the references'/'provide the measuring instruments', and 'that I could not arrange her respondents for her'). Students also projected their fears of being confronted with their research incompetence onto the supervisor ('at conferences I see students duck and dive when they see me', 'they often do not answer my emails'). The above projections stimulated strong feelings among participants ('somehow I like it when they think I know so much', 'I get frustrated when they do not finish in spite of all my efforts to help', 'I get so angry when they do not follow simple rules', 'I wish I could tell them to grow up' yet 'one needs to be careful in what you say' - 'It would be terrible if a student accuses me of wrongdoing and get into more trouble').

From the side, the projections of competence were about support from colleagues ('they tell me that I am a good supervisor', 'they often ask me my opinion about supervision', 'young colleagues have asked to co-supervise with me'). The projections of incompetence were about denigration ('I have been told that I take all the distinction students', 'that I make the students work extra hard', 'when a colleague realised that we will jointly supervise a doctorate student, 
he retracted saying that then he will have to do all the work and only get half the recognition').

Participants projected onto their colleagues. Projections of competence were about praise ('she is just so good at doing this', 'he helps students to produce far beyond their capacity'). Projections of incompetence were about anger, resentment, competition, rivalry, jealousy and envy ('some colleagues have only one or two students and they do not even finish', 'I have supervised and delivered more students than any of my colleagues', 'he has been here for ages and has never delivered a doctoral student', 'she always complains about struggling with incompetent students', 'some seem to deliver M and D’s like a sausage machine’, 'everybody is putting her on a pedestal - I don't understand the fuss').

From above, the projections of competence were about assuming the role of a supervisor with knowledge of the subject, intelligence, rationality, responsibility and loyalty to the subject and the university in order to successfully deliver higher degree research projects ('I suppose they trust me to do the job', 'they seem to appreciate what I do', 'my COD always acknowledges me when one of my students graduates'). The projections of incompetence were about doubt and mistrust ('the system doesn't believe that we can do proper/professional supervision', 'we often get asked how many M and D students we have', 'why the students are working so slowly', 'why our throughput is so low', 'whether we can work harder' and 'take on more students', 'they are always checking up on us', 'especially on school and college level' - 'I had a dream where I lost my job because of this'). For some, the projections of incompetence were about confusion ('I sometimes get confused about what supervision is', 'there are so many side shows' 'distracting me from doing supervision'); and for others about paranoia ('I don't know who to believe anymore', 'I wonder what they want from me', 'it is as if they watch you to make a mistake'). Some participants referred to a combined and conflicting competence/incompetence projection from the institutional authorities ('they use empowerment language like “you know what to do”,' but 'the moment there is a hiccup' they 'come down on you like a ton of bricks' - 'supervision has become the stick to hit us with').

\section{DISCUSSION}

The aim of this research was to study and describe the systems psychodynamic role identity of a group of academic research supervisors.

In their normative role, the academic research supervisors in this study gave convincing evidence of consciously and intellectually understanding the role boundaries of research supervision within academia. It was interpreted that they took up their sophisticated task with consciously managed authority (Cytrynbaum and Noumair 2004, 43-45) from above 
(management) and from below (students), based on their training and experience in their academic role.

The significant differences in the content of their conscious (normative) and unconscious (existential/phenomenal) role parts illustrated a high level of free-floating anxiety (Armstrong and Rustin 2015, 144). This was interpreted as a conflict between their intellectual understanding of the work content and their emotional coping with the complexity of managing the self in role and coping with the other in the system (Obholzer and Roberts 1994, 30).

In their existential role, academic research supervisors experienced high levels of performance anxiety where their good intent and realistic sense of own competence were in conflict with their self-doubt and fear of failure. They struggled to differentiate between their own competence and the success of the student. They over-identified with and personalised their supervision role, which led to taking the outcome as a personal success or failure. The failure often resulted in experiencing guilt and shame (Mollon 2004). Even the variety of research topics, designs and methods were turned into an internal fight about competence and a compulsive need for over-structure to contain their anxiety. The outcome of their students' examination became a test of their own psychological coping. These intrapersonal behaviours had a negative effect on their relationships with their students. Their high levels of performance anxiety led to a compulsive avoidance of the bad object (e.g. the irritating student) (Klein 1997, 3). The academic research supervisors introjected an exaggerated (almost dramatising Blackman 2004, 71) position of not being good enough in the role (Klein 1997, 61-68). Although the above could relate to previous research (Lucey and Rogers 2007, 16) on how unconscious power dynamics negatively influence the supervisor-student relationship, the present findings did not measure if and how research project progress is influenced.

In their phenomenal role, the academic research supervisors received projections of competence when they pleased the needs of the other and of incompetence when they stood up for academic and ethical principles different from the others' needs. This was interpreted as the system using the academic research supervisor as an object to have its personal needs met, while it disregards the academic research supervisor as a subject with its humanity, honesty and scientific principles and drive. Most of the academic research supervisors in this research found it difficult to not identify with the projections (Cytrynbaum and Noumair 2004, 35-36). This manifested as irritation, frustration, anger and fear of failure. On a larger systemic level, it was interpreted that the university system used the academic research supervisors to contain these negative feelings on its behalf (Cytrynbaum and Noumair 2004, 62; Stapley 2006, 34-39). In terms of projections from students, these findings relate to the research by Akala and Backhouse 
(2015). Although they did not interpret unconscious dynamics their findings suggest the powerful effect of students’ gossiping on supervisors.

Unconsciously, the academic research supervisors experienced conflict about whether they are competent and good enough to assume the role. The role seems to contain free-floating, survival, performance, paranoid and persecutory anxiety, which they defended against by using various primitive and sophisticated defensive structures - splitting (the good self from the bad other), regression into childlike behaviour, denial of their qualifications, experience and evidence of their competence, suppression of their aggression towards students, colleagues and management, projection of their fears onto colleagues and rationalisation of the seriousness of not feeling competent to do their work. These experiences are congruent with what the SP literature describes as symptomatic of being under intense emotional pressure in systems working on the primary task of securing specialised excellence (Czander 1993, 294-308), and in this instance, in the academic system domain (Bain 1998, 413).

In terms of basic assumption behaviour, the academic research supervisors expressed their 'longing' dependence on an understanding and parental supportive university leadership system. In its absence they expressed their counter-dependence by offloading their anger onto and blaming the university system for their difficult situation. They tried to pair with colleagues in similar situations and formed cliques, which for some, became a support group (Cytrynbaum and Noumair 2004, 143). Their fight responses indicated their anxiety about failing and ways to establish a clean record and track record (Stapley 2006, 210) and their flight responses manifested as a wish to avoid difficult students, to do more graduate and honours teaching and to leave academia. We-ness manifested in how they referred to themselves in the plural (indicating the fantasy that many colleagues experience the same and are united in doing so) (Cytrynbaum and Noumair 2004, 361). Me-ness manifested mostly when they received 'positive' projections about competence and excellence. The above was interpreted as evidence of the academic research supervisors' high levels of free-floating, performance and paranoid anxiety in performing their task and staying in the role (Clarke, Hahn and Hoggett 2008, 166176).

Furthermore, the academic research supervisors experienced conflict between being competent and incompetent at the same time, using their own sense of good enough academic decision making and relationship management versus what the other expects and projects onto them (Czander 1993, 274-275). Their primary task of supervising the work of their designated individual students was under attack by their introjections of not being good enough for this 'prestigious role' and the incapacitating projections of incompetence onto their role. Some of 
them illustrated off-task behaviour by worrying about their performance, procrastinating and spending time on checking students' spelling and references. Two academic research supervisors, who described themselves as 'having been doing this for a long time', reported on their boredom, which was interpreted as the defence against seeing the opportunities of excitement and novelty in each task or project (Armstrong and Rustin 2015, 70-87). The academic research supervisors' time and ego boundaries were under attack, which caused them performance and survival anxiety. They experienced being de-authorised by the system in various ways - personally, technically, academically and managerially (Cytrynbaum and Noumair 2004, 153-154). The above was interpreted as follows: Academic research supervisors' high level of internal (introjected) and relational (projected) conflict caused high levels of free-floating, performance and paranoid anxiety, which manifested in spells of offtask behaviour, role confusion, difficulty in managing the boundaries of self, time and task, and feeling de-authorised by others using them as containers of their issues.

Using SP guidelines (Armstrong and Rustin 2015, 300-314), the academic research supervisors' experience of survival, performance and paranoid anxiety can be seen as suspiciously intense. Although anxiety among individual supervisors is to be expected, the concern is about its collective intensity leading to such a strong position (Campbell and Huffington 2008, 80-83) of not being good-enough (Klein 1997, 268-274) in role (in spite of qualifications, experience, publication records and status in academia). It was hypothesised that these anxiety experiences were projections from the larger university system onto and into (Huffington et al. 2004, 67-82) its academic research supervisors, based on the following argument: As a macro system, the university’s primary task and normative role is about (economic and financial) survival, performance (of staff and students) and sustainability (Diamond and Allcorn 2009, 13-91). Its unconscious task is to act as a container, holding potential space for its staff and students as clients (Clarke, Hahn and Hoggett 2008, 185-193) to assume (in this case) their academic and supervision roles towards the transformation of the system-as-a-whole (Armstrong 2005, 1-9). Although not directly studied in this research, the participants implied that the large university system expressed anxiety about their performance and its effect on the institution's 'financial bottom line'. Therefore, the present findings suggest that the academic research supervisors' intense anxiety in their phenomenal role about containing a primary task that does not fit their organisational level, does not belong to them, but that it is the larger system's uncontained anxiety being projected. The academic research supervisors as the target of the projection are significant in that their primary task is to secure higher degree throughput, implying large government subsidies. It needs to be mentioned here 
that projections are seen as unconsciously based on trust towards the receiver to preserve the precious projected material and possibly even transform this before it can be owned again (Cytrynbaum and Noumair 2004, 173-174). It is therefore interpreted that through projective identification, the academic research supervisors were used by university leadership to (in additional to their normative and existential roles) carry and process the extremely important large system (university) anxiety about survival, performance and sustainability on behalf of the institution.

In their study of the conscious behaviour of academics Pihouse-Morgan et al. (2016) suggested that collegial relationships are critical to the growth of self-belief and selfresourcefulness in becoming and being academics. The above findings suggest that the wellintended conscious functioning and assumed self-reliance could be eroded by unconscious projective attacks by the larger system.

\section{CONCLUSION}

The systems psychodynamic role identity of academic research supervisors can be characterised as follows: Consciously, they seem to be clear about their roles and they cope with its rational demands by applying their intelligence and relevant training. Unconsciously, they experience different kinds and intensities of anxiety. These refer to their introjected incompetence and notgood-enough-position which have a negative effect on their relationships with their students. Furthermore, they receive conflicting projections - about competence when it serves the other and about incompetence where the other projects their unwanted anxieties onto and into the academic research supervisors.

The implication of these findings can be framed as follows. It is clear that academic supervision creates strong (unconscious) anxiety amongst supervisors that are not addressed or processed in the day-to-day execution of the work towards catharsis and understanding of what this says about themselves (their introjections) or where it could possibly come from (their received projections), they become stuck in a system domain position of acting as containers of the larger university's projected anxiety as well as what students and colleagues unconsciously represent for them as objects. It can be hypothesised that this scenario keeps supervisors trapped in irrational and impersonal object relations with their students, colleagues and the university as a system.

\section{Limitations}

The sample in this study was from one institution with its limiting broader application. 
Hopefully the findings can be transferred to similar institutions - which the readers will have to decide on. The researcher, as an academic and involved in academic research supervision, had to guard against being seduced out of the researcher role. The inputs from the independent psychologist (see above) and the rationality of the SP stance hopefully provided sufficiently effective containers for interpretation purposes. It could also be argued that the supervisors' students needed to be included in this research project, to which the SP stance would comment as follows. The students, colleagues, management and the institution mentioned by the academic supervisors are studied in their unconscious object representation and not as subjects (people or individuals).

\section{Recommendations}

For this and similar universities, it was recommended that leadership reflect on the findings in a facilitated session to ensure their understanding of and insight into the unconscious dynamics. The outcome of such of session could be for leadership to introspect on their own survival anxiety as an institution, and to own that in differentiation of what research supervisors' roles hold. Thus, leadership will be assisted in taking back their projections from the academic research supervisors as containers of larger systemic anxiety which will hopefully facilitate insight into the larger systemic dynamics belonging to the senior institutional roles.

For academic research supervisors, it was recommended that systems psychodynamic experiential sessions be incorporated in their continuous training to facilitate awareness of how they are unconsciously impacted by the other objects-in-the-mind (students, colleagues, management) and vice versa. These sessions can focus on how the individual supervisor takes up the unconscious part of the role while they are encouraged to explore (1) the origin of their introjections as unconscious patterns which have developed in childhood and are presently manifesting as repetition compulsions and transferences, and (2) the nature of their received projections and their valence to act on specific kinds of projections which they contain (as 'dumping grounds') on behalf of the system, which also represents their own authority and sibling objects. In exploring and processing these unconscious experiences the supervisors can see themselves, their students and the university system less as irrational unconscious objects and more as realistic subjects in need of forming authentic relationships with. It was hypothesised that this 'new' position would avail the supervisor in role as more objective and rational facilitators of learning to their students and the university.

It was also recommended that more research be conducted on the academic research supervisors' role as an SP object to ascertain its unconscious representation in a university as a 
complex organisational system. It is suggested that the role has become pivotal in ensuring systemic survival and that it may have developed a valence for containing systemic anxiety relating to rivalry, competition and envy.

\section{REFERENCES}

Adler, P. A. and P. Adler. 2005. The identity career of the graduate student: Professional socialisation to academic sociology. The American Sociologist 36(2): 11-17.

Aguinis, H. and M. S. Nesler. 1996. Power bases of faculty supervisors and educational outcomes. Journal of Higher Education 67(3): 267-297.

Akala, B. and J. Backhouse. 2015. 'They can't even agree!' Student conversations about their supervisors in constructing understanding of the $\mathrm{PhD}$. South African Journal of Higher Education 29(4).

Alvesson, M. and K. Sköldberg. 2010. Reflexive methodology: New vistas for qualitative research. London: Sage.

Armstrong, D. 2005. Organisation in the mind: Psychoanalysis, group relations and organisational consultancy. London: Karnac.

Armstrong, D. and M. Rustin. 2015. Social defences against anxiety: Explorations in a paradigm. London: Karnac.

Armstrong, S. J. 2004. The impact of supervisors' cognitive styles on the quality of research supervision in management education. British Journal of Educational Psychology 74(4): 599-617.

Armstrong, S. J., C. W. Allinson and J. Hayes. 2004. The effects of cognitive style on research supervision: A study of student-supervisor dyads in management education. Academy of Management Learning and Education 3(1): 41-63.

Bain, A. 1998. Social defences against organisational learning. Human Relations 51(3): 413-429.

Blackman, J. S. 2004. 101 Defences: How the mind shields itself. New York: Brunner-Routledge.

Brunner, L. D., A. Nutkevitch and M. Sher. 2006. Group relations conferences: Reviewing and exploring theory, design, role-taking and application. London: Karnac.

Campbell, D. and M. Groenbaek. 2006. Taking positions in the organisation. London: Karnac.

Campbell, D. and C. Huffington. 2008. Organisations connected: A handbook of systemic consultation. London: Karnac.

Chiappetta-Swanson, C. and S. Watt. 1999. Good practice in the supervision and mentoring of postgraduate students: It takes an academy to raise a scholar. New York: McMaster University.

Chikte, U. M. E. and J. A. Chabilall. 2016. Exploration of supervisors and student experiences during master's students in a health science faculty. South African Journal of Higher Education 30(1): 57-79. http://dx:doi.org/10.20853/30-1-559

Clarke, S., H. Hahn and P. Hoggett. 2008. Object relations and social relations: The implications of the relational turn in psychoanalysis. London: Karnac.

Clarke, S. and P. Hoggett. 2009. Researching beneath the surface: Psycho-social research methods in practice. London: Karnac.

Coldwell, D., E. Papageorgiou, C. Callaghan and A. Fried. 2016. Academic citizenship and wellbeing: An exploratory cross-cultural study of South African and Swedish academic perceptions. South African Journal of Higher Education 30(1): 80-105. http://dx:doi.org/10.20853/30-1-555

Colman, A. D. and W. H. Bexton. 1975. Group relations reader 1. Jupiter, FL: A.K. Rice Institute.

Colman, A. D. and M. H. Geller. 1985. Group relations reader 2. Jupiter, Fl: A.K. Rice Institute.

Conrad, C. F., J. Duren and J. G. Haworth. 2002. Student's perspectives on their master's degree 
experiences: Disturbing the conventional wisdom. New Directions in Higher Education 101: 6576.

Curtis, H. 2015. Everyday life and the unconscious mind: An introduction to psychoanalytic concepts. London: Karnac.

Cytrynbaum, S. and A. Noumair. 2004. Group dynamics, organizational irrationality, and social complexity: Group relations reader 3. Jupiter, FL: A.K. Rice Institute.

Czander, W. M. 1993. The psychodynamics of work and organizations. New York: Guilford.

Damonse, B. and M. Nkomo. 2012. Leading form the front: Exploring the professional and personal nature of research leadership. South African Journal of Higher Education 26(3).

De Vos, A. S., H. Strydom, C. B. Fouche and C. S. L. Delport. 2002. Research at grass roots: For the social sciences and human service professions. Pretoria: Van Schaik.

Denholm, C. T. and T. Evans. 2007. Supervising doctorates downunder. Camberwell, Australia: ACER.

Diamond, M. A. and S. Allcorn. 2009. Private selves in public organisations: The psychodynamics of organisational diagnosis and change. New York: Palgrave Macmillan.

Emilsson, U. M. and E. Johnsson. 2007. Supervision of supervisors: On developing supervision in postgraduate education. Higher Education Research and Development 26(2): 163-179. DOI:10.1080/07294360701310797.

Ferris, W. P. 2002. Students as junior partners, professors as senior partners, the B-school as the firm: A new model for collegiate business education. Academy of Management Leading and Education 1(2): 185-193.

Ferris, W. P. 2003. Why the partnership model's usefulness far exceeds that of the client model: Reply to Armstrong. Academy of Management Learning and Education 2(4): 375-377.

French, R. and R. Vince. 1999. Group relations, management and organisation. Oxford: Oxford University Press.

Gordon, P. J. 2003. Advising to avoid or to cope with dissertation hang-ups. Academy of Management Learning and Education 2(2): 181-187.

Gordon, R. M. 1995. The symbolic nature of the supervising relationship: Identification and professional growth. Issues in Psychoanalytic Psychology 17(2): 154-166.

Govender, K. K. and S. Ramroop. (2013). The relationship between the postgraduate research climate, role clarity and research service quality: exploring the supervisors' and students' perceptions. South African Journal of Higher Education 27(1).

Graneheim, U. H. and B. Lundman. 2004. Qualitative content analysis in nursing research: Concepts, procedures and measures to achieve trustworthiness. Nurse Education Today 24: 105-112.

Grant, B. 2003. Mapping the pleasures and risks of supervision. Discourse: Studies in the Cultural Politics of Education 24(2): 174-190. DOI: 10.1080/0159630032000110720.

Green, B. and A. Lee. 1995. Theorising postgraduate pedagogy. Australian Universities Review 38: 4045.

Grossman E. S. 2016. 'My supervisor is so busy ...'. Informal spaces for postgraduate learning in the health sciences. South African Journal of Higher Education 30(2): 94-109. http://dx:doi.org/10.20853/30-2-643

Haamer, A., L. Lepp and E. Reva. 2012. The dynamics of professional identity of university teachers: Reflecting on the ideal university teacher. Studies for the Learning Society 2(2-3): 110-120.

Halse, C. and P. Bansel. 2012. The learning alliance: Ethics in doctoral supervision. Oxford Review of Education 38(4): 377-392. DOI: 10.1080/03054985.2012.706219

Hirschhorn, L. 1997. Reworking authority: Leading and following in the post-modern organisation. London: MIT.

Hockey, J. 1996. Motives and meaning amongst PhD supervisors in the social sciences. British Journal of Sociology of Education 17(4): 489-506. 
Hollway, W. and T. Jefferson. 2010. Doing qualitative research differently: Free association, narrative and the interview method. Los Angeles: Sage.

Huffington, C., D. Armstrong, W. Halton, L. Hoyle and J. Pooley. 2004. Working below the surface: The emotional life of contemporary organisations. London: Karnac.

Kam, B. H. 1997. Style and quality in research supervision: The supervisor dependency focus. Higher Education 34(1): 81-103.

Kets de Vries, M. F. R., K. Korotov and E. Florent-Treacy. 2007. Coach and couch: The psychology of making better leaders. London: Palgrave.

Klein, L. 2005. Working across the gap: The practice of social science in organisations. London: Karnac.

Klein, M. 1997. Envy and gratitude and other works 1946-1963. London: Vintage.

Leavy, P. 2014. The Oxford handbook of qualitative research. Oxford: Oxford University Press.

Lee, A. 2012. Successful research supervision: Advising students doing research. London: Routledge.

Lepp L., M. Remmik, A. Leijen and M. Karm. 2010. Through hardships to the stars: Experiences of doctoral thesis supervisors about their doctoral studies and connections with their supervising practice. http://eha.ut.ee/wp-content. Accessed 20 January 2016.

Lizzio, A. and K. Wilson. 2004. Action learning in higher education: An investigation of its potential to develop professional capability. Studies in Higher Education 4: 469-488.

Long, S. 2006. Organizational defenses against anxiety: What has happened since the 1995 Jaques paper? International Journal of Applied Psychoanalytic Studies 3(4): 279-295. DOI:10.1002/aps.111.

Long, S. 2008. The perverse organisation and its deadly sins. London: Karnac.

Long, S. 2013. Socio-analytic methods: Discovering the hidden in organisations and social systems. London: Karnac.

López-Corvo, R. E. 2003. The dictionary of the work of W. R. Bion. London: Karnac.

Lucey, H. and C. Rogers. 2007. Power and the unconscious in doctoral-supervisor relationships. In Institutional is political, ed. V. Gillies, 16-36. London: Palgrave Macmillan.

Mackinnon, J. 2004. Academic supervision: Seeking metaphors and models for quality. Journal of Further and Higher Education 28(4): 395-405.

Marcketti, S. B., M. W. Mhango and M. B. Gregoire. 2006. The experiences of African graduate students in a College of Human Sciences. Journal of Family and Consumer Sciences Education 24(1): 6372.

McNamara, C. 2014. Typical experiences of a first-time supervisor. Online integrated library for personal, professional and organizational development. www.academic.supervisors'. experiences (accessed 16 December 2014).

Mmako, M. and C. Schultz. 2016. An employee engagement framework for technical vocational education and training colleges in South Africa. South African Journal of Higher Education 30(2): 143-163. http://dx:doi.org/10.20853/30-2-606

Mollon, P. 2004. Shame and jealousy: The hidden turmoils. London: Karnac.

Murphy, E. and E. Coleman. 2004. Graduate students' experiences of challenges in online asynchronous discussions. Canadian Journal of Learning and Technology 30(2): 1-9.

Neumann, J. E., K. Kellner and A. Dawson-Shepherd. 1997. Developing organisational consultancy. London: Routledge.

Obholzer, A. and V. Z. Roberts. 1994. The unconscious at work. London: Routledge.

Oost, H. and H. Sonneveld. 2007. Selected readings on PhD supervision. Amsterdam: Netherlands Centre for Research Schools and Graduate Schools.

Petersen, E. B. 2014. Re-signifying subjectivity? A narrative exploration of 'non-traditional' doctoral 
students' experience of subjective formation through two Australian cases. Studies in Higher Education 39(5): 823-834. DOI: 10.1080/03075079.2012.745337

Pithouse-Morgan, K., L. Masinga, I. Naicker, T. Hlao and D. Pillay. 2016. ‘Sink or swim?’: Learning from stories of becoming academics within a transforming university terrain. South African Journal of Higher Education 30(1): 224-244). http://dx:doi.org/10.20853/30-1-561

Popov, O. 2009. Teacher's and student's experiences of simultaneous teaching in an international distance and on-campus master's programme in engineering. International Review of Research in Open and Distance Learning 10(3): 1-8.

Sievers, B. 2009. Psychoanalytic studies of organizations. Contributions from the International Society for the Psychoanalytical Study of Organizations (ISPSO). London: Karnac.

Sonn, R. 2016. The challenge for a historically disadvantaged South African university to produce more postgraduate students. South African Journal of Higher Education 30(2): 226-241. http://dx:doi.org/10.20853/30-2-601

Stapley, L. F. 2006. Individuals, groups and organisations beneath the surface. London: Karnac.

Terre Blanche, M., K. Durrheim and D. Painter. 2006. Research in practice: Applied methods for the social sciences. Cape Town: UCT Press.

Trafford, V. and S. Leshem. 2010. Stepping stones to achieving your doctorate: Focusing on your viva from the start. Maidenhead, UK: Open University Press.

Van Biljon, J. A. and M. R. De Villiers. 2013. Multiplicity in supervision models: The supervisor's perspective. South African Journal of Higher Education 27(6).

Van Laren, L., K. Pithouse-Morgan, T. Chisanga, L. Harrison, T. Meyiwa, N. Muthukrishna, I. Naicker and L. Singh. 2014. 'Walking our talk': Exploring supervision of postgraduate self-study research through metaphor drawing. South African Journal of Higher Education 28(2).

Waghid, Y. 2015. Dancing with doctoral encounters. Democratic education in motion. Stellenbosch: Sun Press.

Wagner, C., B. Kawulich and M. Garner. 2012. Doing social research: A global context. London: McGraw-Hill.

White, N. W. 2007. 'The customer is always right?' Student discourse about higher education in Australia. High Education 54: 593-604. DOI 10 1007/s10734-006-9012-x.

Wright, A., J. P. Murray and P. Geale. 2007. A phenomenographic study of what it means to supervise doctoral students. Academy of Management Learning and Education 6(4): 458-474.

Zinkin, L. 1989. The group as container and contained. Group Analysis 22: 227-234. 